\title{
CURRENT ISSUES ON PRA REGARDING SEISMIC AND TSUNAMI EVENTS AT MULITI UNITS AND SITES BASED ON LESSONS LEARNED FROM TOHOKU EARTHQUAKE/TSUNAMI
}

\author{
KATSUMI EBISAWA ${ }^{1 *}$, MASATOSHI FUJITA ${ }^{2}$, YOKO IWABUCHI ${ }^{3}$, and HIDEHARU SUGINO ${ }^{4}$ \\ ${ }^{1}$ Associate Vice-President, Japan Nuclear Energy Safety Organization (JNES), Incorporated Administrative Agency \\ Toranomon Towers Office, 4-1-28 Toranomon, Minato-ku, Tokyo, Japan \\ ${ }^{2}$ Seismic Safety Division, JNES, ditto \\ ${ }^{3}$ Seismic Safety Division, JNES, ditto \\ ${ }^{4}$ Seismic Safety Division, JNES, ditto \\ *Corresponding author. E-mail : ebisawa-katsumi@jnes.go.jp
}

Received May 07, 2012

The Tohoku earthquake (Mw9.0) occurred on March 11, 2011 and caused a large tsunami. The Fukushima Dai-ichi NPP (F1-NPP) were overwhelmed by the tsunami and core damage occurred. This paper describes the overview of F1-NPP accident and the usability of tsunami PRA at Tohoku earthquake. The paper makes reference to the following current issues: influence on seismic hazard of gigantic aftershocks and triggered earthquakes, concepts for evaluating core damage frequency considering common cause failure with correlation coefficient against seismic event at multi units and sites, and concepts of "seismic-tsunami PSA" considering a combination of seismic motion and tsunami effects.

KEYWORDS : Tohoku Earthquake/Tsunami, Fukushima Dai-ich NPP Accident, Seismic Event, Tsunami Event, Multi Units and Sites, PRA, Gigantic Aftershock, Triggered Earthquake, Common Cause Failure, Correlation Coefficient

\section{INTRODUCTION}

The Tohoku earthquake (Mw9.0) occurred at 14:46 on March 11, 2011 and caused a large tsunami. The strong seismic motion was observed at the Fukushima Dai-ichi Nuclear Power Plant (F1-NPP) of the Tokyo Elec. Power Co. (TEPCO) and reactors were shut down after control rods had been inserted. While the reactors were shut down normally, they were then overwhelmed by the tsunami about 46 minutes after the earthquake occurred. The various components of the water intake system and emergency diesel generators were flooded. External power supply was also lost due to damage by strong seismic motions and the tsunami. In this situation, station blackout occurred. As a consequence, reactor cooling system functions were lost, core damage (CD) occurred and radioactive materials were released to the off-site area [1].

In risk evaluation practice for seismic and tsunami events, no consideration has been given to the dependency of seismic ground motion effects and/or tsunami effects with seismic PRA and tsunami PRA having been developed independently for efficiency [2],[3]. The accident scenarios described in the seismic PRA implementation standard [4] highlighted these issues when describing the Niigata-ken Chuetsu-oki Earthquake (NCO EQ) [5]. It clearly showed further usability of seismic PSA. One of the authors described the current status and important issues on seismic hazard evaluation methodology in Japan based on lessons learned from the NCO, EQ [6].

The accident scenarios of tsunami PRA developed more than a year ago clearly identified the issues related to the F1-NPP incident [5]. It definitively showed further usability of tsunami PRA method.

The current issues related to seismic PRA and tsunami PRA, based on lessons learned from the F1-NPP accident, are as follows: [7].

- Influence on seismic hazard to gigantic aftershock

- Influence on seismic hazard to triggered earthquake

- Methodology for evaluating core damage frequency at multi units and sites

- Development of "seismic-tsunami PSA (S-TPSA)" considering combination of seismic motion and tsunami effects

This paper describes the overview of the F1-NPP accident. The paper highlights the usability of seismic PRA at the Niigata-ken Chuetsu-oki Earthquake and 


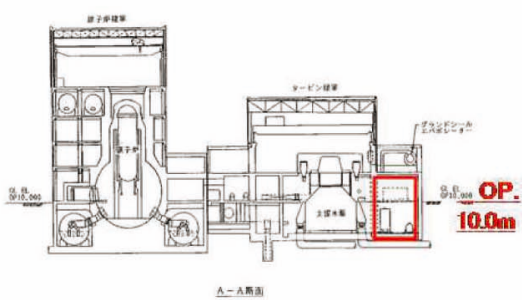

(a) Reactor building

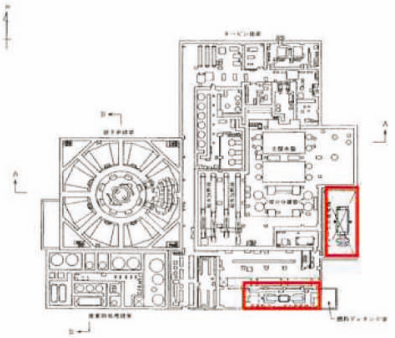

(b) Turbine building

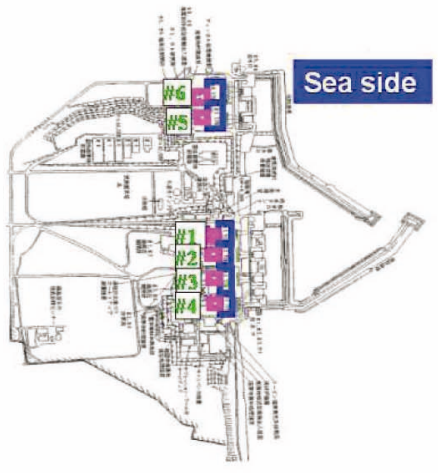

(c) Location of F1-NPP

Fig. 1. (a)-(c) Location of Fukushima Dai-ichi Nucle Power Plant
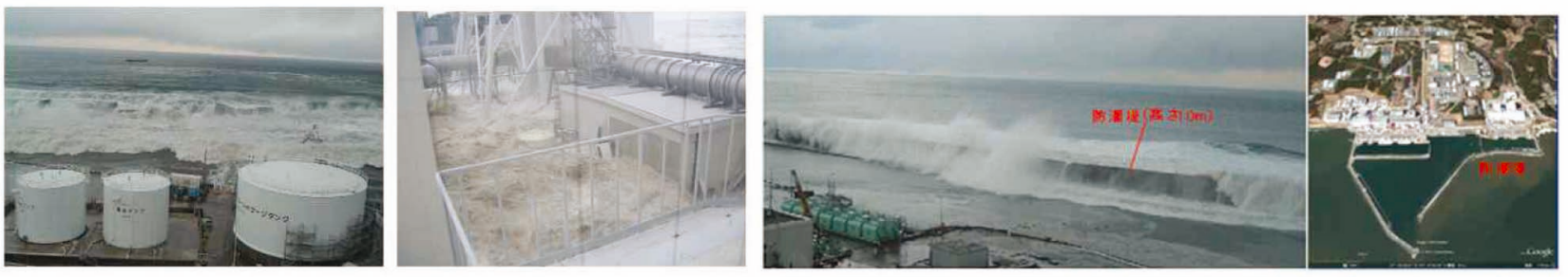

Fig. 2. Situation of Tsunami (by Tokyo Elee. Power Co., 2011)

tsunami PRA at the Tohoku Earthquake. Furthermore, the paper also makes reference to the above current issues.

\section{OVERVIEW OF FUKUSHIMA NPP ACCIDENT AND LESSONS LEARNED FROM THE ACCIDENT}

\subsection{Overview of F1-NPP Accident at Tohoku Earth- quake/Tsunami [1], [5], [7]-[9]}

\subsubsection{Outline of F1-NPP and Tsunami System Ob- served Tsunami}

The F1-NPP is a multi-unit site with 6 BWRs as shown in Fig. 1 (a)-(c). Figure 1(a) shows the location of each unit. Figure (b) and (c) are the EW and NS sections of reactor and turbine buildings respectively. The turbine buildings stand directly by the sea. The emergency diesel generators are installed in the basement of these turbine buildings.

F1-NPP was overwhelmed by a tsunami about 46 minutes after the earthquake, as shown in Fig. 2. The tide level observation system consists of the tide gauge and the recording device in the building. The arrival time and tsunami height of the first large wave was $41 \mathrm{~min}$. after the main shock and O.P. of about $4 \mathrm{~m}$, respectively. The arrival time and tsunami height of the second large wave were $8 \mathrm{~min}$ after the first wave with wave height unknown due to tide gauge failure. The maximum scale of the tide gauge is $7.5 \mathrm{~m}$. The tsunami height was so high that the experts estimated it to be more than $10 \mathrm{~m}$ from a photograph showing the overflow status of tsunami seawall $(10 \mathrm{~m})$ in Fig.2.

\subsubsection{Design Tsunami Height and Site Height}

TEPCO divided the evaluation of the design tsunami height into two stages. Firstly TEPCO evaluated based on the Japanese Society Civil Engineering (JSCE) guide (JSCE, 2002), assessing Shioyazaki EQ. as M7.9, and the highest water level of each unit was set as $5.4 \mathrm{~m}$. TEPCO assessed Shioyazaki EQ. as M8.0 voluntary and the highest water level was set as $5.7 \mathrm{~m}$.

\subsubsection{Damage of NPP}

As to the sea water pump facilities for component cooling (height: 5.6 to $6 \mathrm{~m}$ ), all units were flooded by the tsunami as shown in Fig. 3. Whether or not they were damaged by wave power is under investigation. The Emergency Diesel Generators (EDGs) and switchboards installed in the basement floor of the reactor and the turbine buildings (height: 0 to $5.8 \mathrm{~m}$ ) were flooded except for 

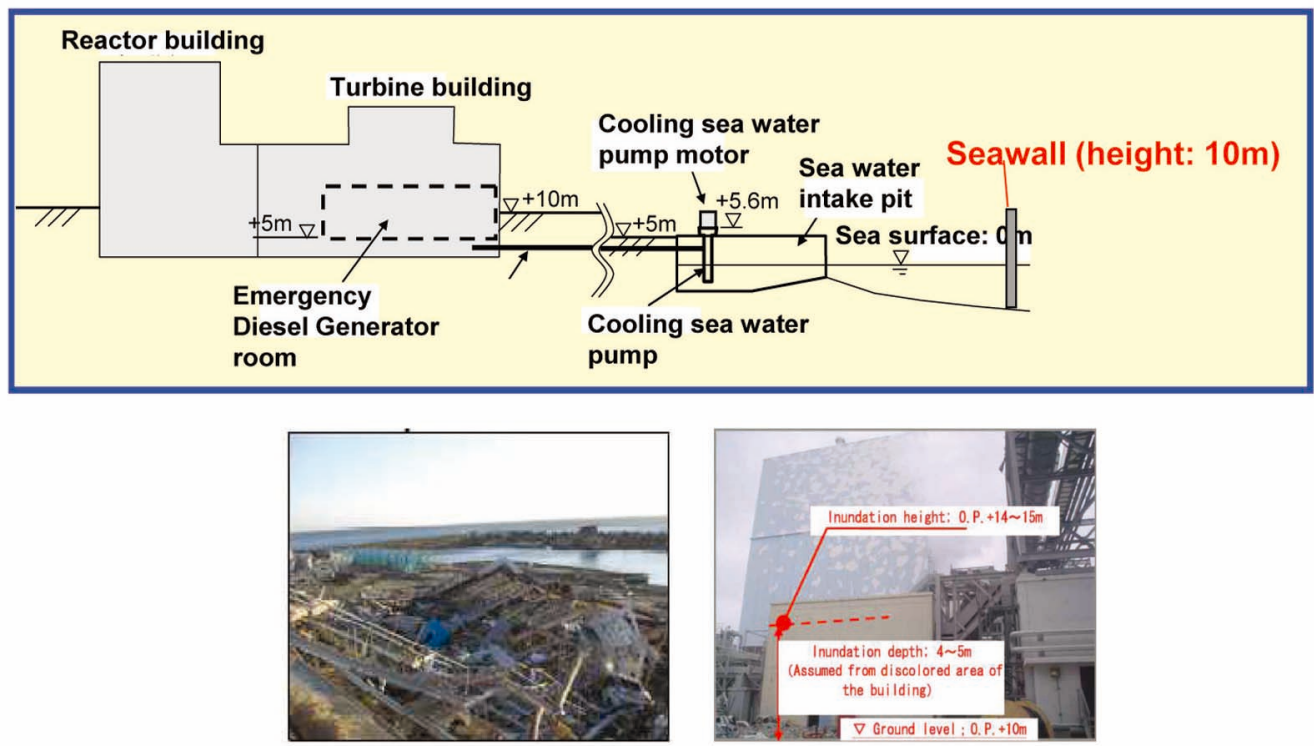

Fig. 3. Illustration of Sea Water Supply System and Situation of Tsunami Disaster at Fukushima Daiichi Nuclear Power Plant (by Tokyo Elec. Power Co., 2011)

Unit 6, and the emergency power source supply (EPS) was lost. Regarding Unit 6, two out of three EDGs were installed in the first basement of the RB and were flooded, but one DG installed on the first floor of DG building was not flooded and EPP supply was possible. A transmission line tower off-site collapsed, and the power supply around the immediate area was lost.

On the other hand, the reactor core isolation cooling system (RCIC), which is a steam-driven cooling system, in the front line (FL) was operationalbut stopped after a short time of operation. Cooling systems in FL other than RCIC (and high pressure coolant injection system (HPCI) or isolation condenser (IC)) were not operated due to a loss of AC power. Failure of reactor core cooling resulted in core damage (core melt) in about 5 or 6 hours. Temperature and pressure in the primary containment vessel rose up, and radioactive materials were released through seals into the power plant and then the surrounding area. Consequently, a wide area was contaminated by the radioactive materials.

\subsection{Lessons Learned from the F1-NPP Accident}

The current issues of seismic engineering based on lessons learned from F1-NPP accident are as follows:

i) Occurrence of gigantic main earthquake and tsunami, a combination of seismic hazard and tsunami hazard

ii) Consideration of gigantic aftershock and triggered earthquake

iii) External events risk evaluation at multi-units and sites

iv) Combined emergency of both natural disaster and the nuclear accident v) Core damage over a short period of time based on functional failure of support systems(seawater supply, power supply and signal systems)

vi) Common cause failure of multi structures and components

vii) Dependency among neighboring units

The contents related to the issue i), iii), v) and vi) are described in section 5.4. The aftershock issue ii) is discussed in section 5.1. The triggered earthquake issue ii) is explored in section 5.2. The contents related to the issue iii), v), vi) and vii) are found in section 5.3. The treatment of issue iv) recommends referencing the paper [10-11].

\section{OUTLINE OF SEISMIC PRA AND ITS USABILITY [2], [5], [7]}

\subsection{Seismic PSA Procedure}

The procedure of seismic PSA consists of 5 steps as shown in Fig.4.

- Step 1: Collection of information related to earthquakes and the setting of accident scenarios

- Step 2: Seismic hazard evaluation

- Step 3: Fragility evaluation

- Step 4: Accident sequence evaluation

- Step 5: Documentation

\subsection{Collection of Information Related to Earthquake and Setting of Accident Scenario}

The collection of information related to earthquakes 


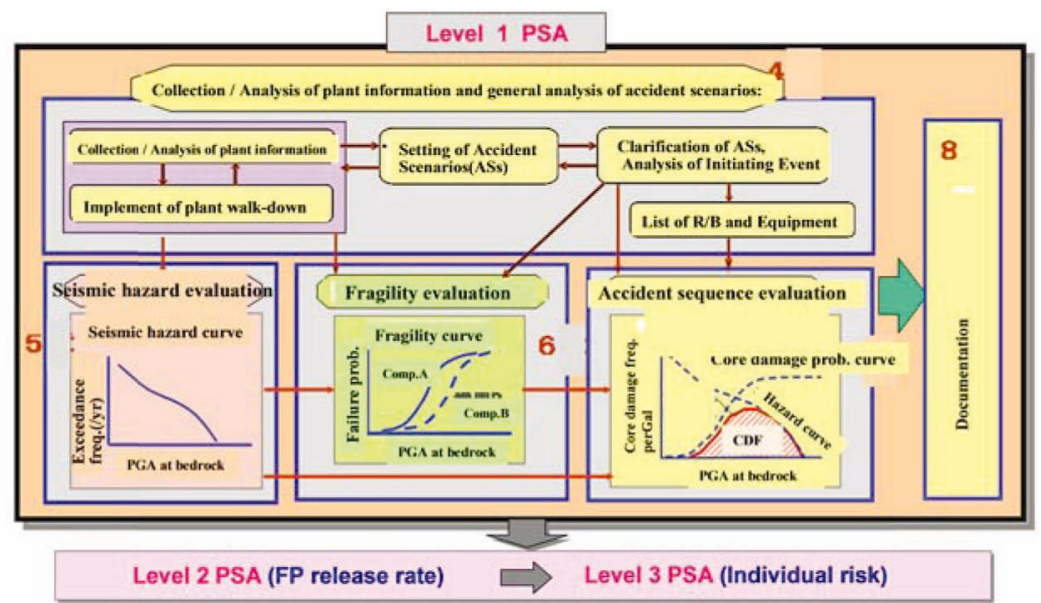

Fig. 4. Procedure of Seismic PSA

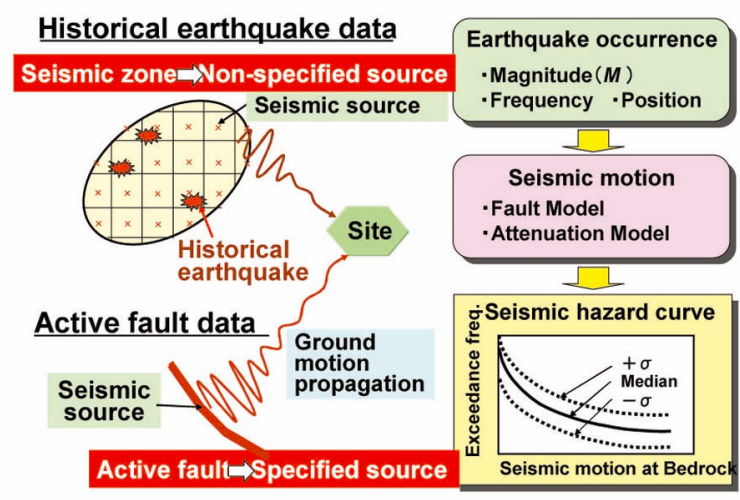

Fig. 5. Procedure of Seismic Hazard Evaluation

and the setting of accident scenarios is shown in Fig.4. First, relevant information should be gathered. Then, a "plant walk-down" based on the gathered information should be conducted. Finally, various accident scenarios based on gathered relevant information and results of the "plant walk-down" should be set.

\subsection{Seismic Hazard Evaluation}

The seismic hazard evaluation is shown in Fig.5. In the evaluation of seismic hazard, "specified source models" for active faults and set "zone source models" for diffuse seismicity should be set. Strong motions are evaluated from these source models by using a propagation model (fault model method and attenuation model).

Then, the evaluation of the seismic hazard should be considered "aleatory uncertainty" and "epistemic uncertainty". The former derives from phenomenology and the latter derives from a lack of recognition and information. The epistemic uncertainties exist in the source models and propagation models of seismic motion as described

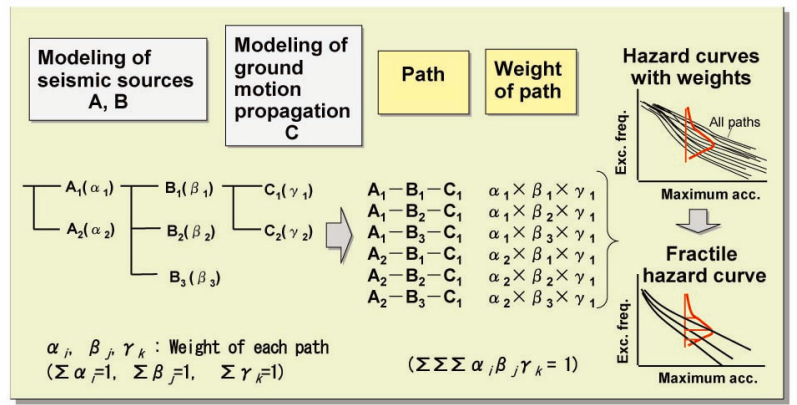

Fig. 6. Outline of Logic Tree

above. Evaluation of epistemic uncertainty is conducted by using a logic tree (LT) with this epistemic uncertainty as a target as shown in Fig. 6.

\subsection{Fragility Evaluation}

(1) Targeted Structures and components

In the evaluation method of fragility, targeted buildings, structures and components are those classified as "class $\mathrm{S}$ " which is the most important class on seismic safety as shown in Fig. 7. Those classified as "class B" and "class C" which would affect safety are targeted as well. These buildings, structures and components include reactor buildings, outside structures and inside components. Inside components are categorized as static and dynamic components. Each category consists of mechanical and electrical system components.

On the Seismic PSA, 200 structures and components are targeted for evaluation within 50 areas on the fault tree.

(2) Fragility evaluation method

The fragility evaluation method is conducted by using components installed in a reactor building as shown in Fig. 8. In the response evaluation of this component, the seismic motion at the bedrock is set up. Then, the response 


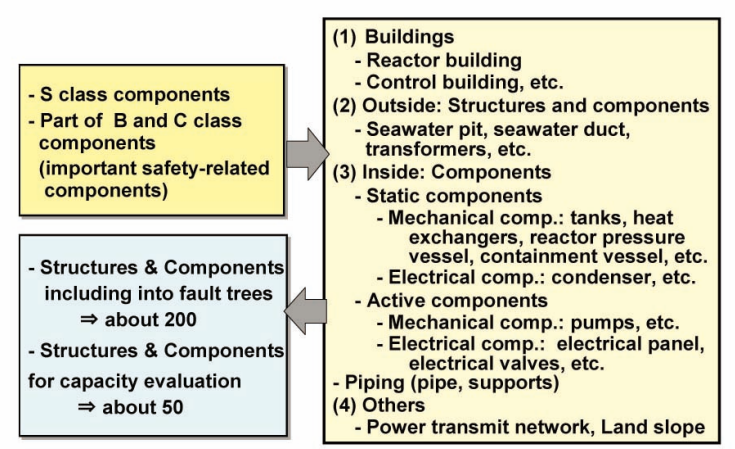

Fig. 7. Structures and Components to be Evaluated

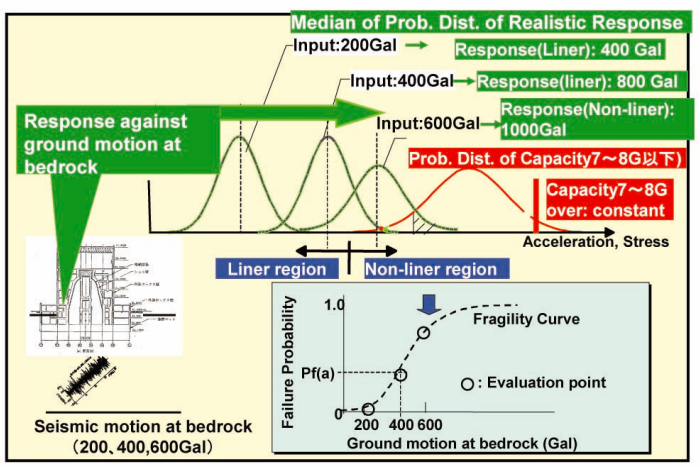

Fig. 8. Procedure of Fragility Evaluation
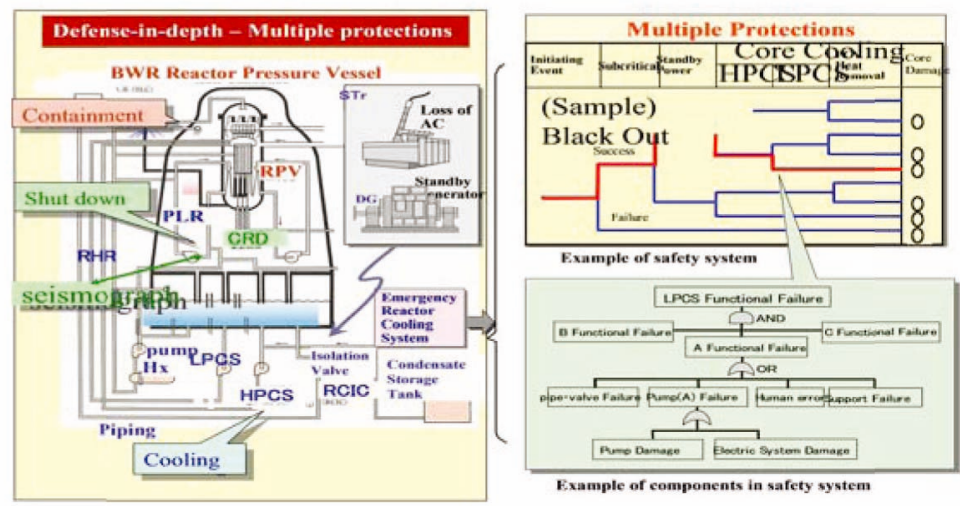

Fig. 9. Accident Sequence Evaluation

analysis of soil, buildings and components against this seismic motion is conducted and evaluation is made, factoring in dispersion. On the fragility evaluation, seismic motion level at the bedrock would be increased by 200 Gal, $400 \mathrm{Gal}$, and $600 \mathrm{Gal}$, and distribution of each response is derived. Fragility curves are obtained as the conditional probability that the realistic response of the component exceeds its capacity as shown in the figure. The capacity of targeted components is evaluated to include dispersion.

On the fragility evaluation, the evaluation of functional failure limit of structures and components on the capacity evaluation is extremely important.

\subsection{Accident Sequences Evaluation}

In cases of needing to evaluate accident sequences, the sequences are represented by using an event tree based on various accident scenarios considered in Chapter 4. The developed fault trees that consist of each event tree are shown in Fig. 9.

Core damage probabilities (CDPs) are evaluated by using event trees, fault trees and by examining the fragilities of components as shown in Fig. 10. The CDF is estimated by multiplying the seismic hazard curve per Gal by CDP

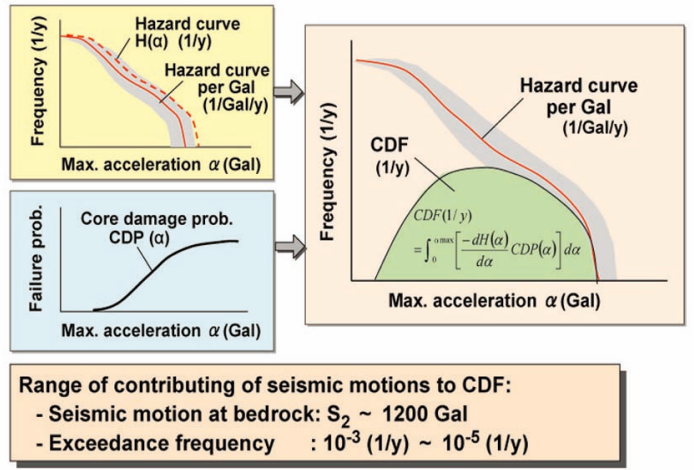

Fig. 10. Procedure of Core Damage Frequency (CDF) evaluation and Range of Seismic Motions Dominantly Contributing to CDF

curve, which then corresponds to a semicircular shape area that is calculated by the integration of seismic motion acceleration (Gal).

\subsection{Usability of Seismic PSA}

The Niigata-ken Chuetsu-Oki earthquake (NCO) occurred in the vicinity of Kashiwazaki-Kariwa NPP 
Table 1. Comparison Table of Accident Scenario of Seismic PSA and Kashiwazaki-Kariwa NPP

\begin{tabular}{|c|c|}
\hline $\begin{array}{l}\text { Examples for wide range of Accidental Scenario described in } \\
\text { the Standard for Procedure of Seismic PSA } 2007 \text { (AESJ) }\end{array}$ & Damage Status of NPP by NCOE \\
\hline A. Effect on Core Damage by Main Shock & \\
\hline \begin{tabular}{|l|l|} 
A1.Direct Effect & (1)SSCs having Safety Function \\
(Damage of As, A Facilities)
\end{tabular} & \multirow{3}{*}{$\begin{array}{l}\text { (1) (Unit 6) Damage of connection part of } \\
\text { wheel axis of Overhead Traveling } \\
\text { Center } \\
\text { (2) (Unit 4) Crack on connection part of } \\
\text { Condenser, Sea water Leakage } \\
\text { (Unit 7) Degradation of water-tightness } \\
\text { of watertight door on RCIC and RHR } \\
\text { System } \\
\text { (Unit 3) Come off of Blow Out Panel of } \\
\text { R/B } \\
\text { (3) None } \\
\text { (4) Incline of Stack, Shift of Duct } \\
\text { (5) Partial land slide of slope in the east } \\
\text { side of Switchyard } \\
\text { (6) None } \\
\text { (7) None. Floods in the basement of } \\
\text { Building by Breakage of Piping for Fire } \\
\text { Extinction }\end{array}$} \\
\hline $\begin{array}{l}\text { A2-1 Other than SSCs having Safety Function (Secondary } \\
\text { effects may affect As, A facilities directly to lead Core Damage) }\end{array}$ & \\
\hline $\begin{array}{l}\text { - Indoor Facilities } \\
\text { (1) Effect on CV and PV by falling and dropping of Overhead } \\
\text { Traveling Crane } \\
\text { (2) Effect on As, A facilities by damaging of B, C facilities } \\
\text { (3) Effect on adjacent Building by Turbine Missile } \\
\text { - Outdoor Facilities } \\
\text { (4) Effect on buildings by falling of Stack } \\
\text { (5) Effect on Buildings and Surrounding Facilities by Possible } \\
\text { Collapses of the Surrounding Grounds above the foundation } \\
\text { (6) External Power Source Loss by Damages of Power Line Towers } \\
\text { of Power Grids } \\
\text { (7) Function Loss of Cooling by stopping Industrial Water Supply }\end{array}$ & \\
\hline $\begin{array}{l}\text { A2-2 Effect on Human Error } \\
\text { (8) Incorrect operation introduced by highly stressed operators and } \\
\text { workers during and after earthquakes } \\
\text { (9)Trouble of backup operation by blackouts for Damage of } \\
\text { Insulator of Transformer } \\
\text { (10Trouble of transportation on site by soil liquefaction and damage } \\
\text { of retaining wall } \\
\text { (11)Effect to operators by Damage of Secondary members of Sealing } \\
\text { (11)Mistakes on Plans and Designs, Selecting Materials, } \\
\text { Manufacturing and Building to Completion of Facilities }\end{array}$ & $\begin{array}{l}\text { (8) Unit 7) lodine detected at main exhaust } \\
\text { tower in periodic measurement } \\
\text { (9)(Unit 3) Fire broke out at Auxiliary } \\
\text { Transformer 3B } \\
\text { (Unit 3,4,6) Oil leakage of Auxiliary } \\
\text { Transformer 3B } \\
\text { (10) Caving in yard } \\
\text { (11) Dropping of secondary members of } \\
\text { Sealing }\end{array}$ \\
\hline $\begin{array}{r}\text { B. Effect on Core Damage by Aftershocks } \\
\text { (13) Evaluate Increase of } \\
\text { CDF by Aftershocks }\end{array}$ & \\
\hline
\end{tabular}

(KK-NPP) in July 2007. The KK-NPP consists of 7 reactor units. Seismometers had been installed in and outside of buildings and many seismic motions are recorded.

Table 1 shows the comparison between the accident scenario of seismic PSA and the accidental event that occurred at the NCO earthquake. The accident scenario of seismic PSA was described in the seismic level -1 PSA Implementation standards that were compiled by the Atomic Energy Society of Japan in March 2007, one and a half years before the occurrence of the NCO earthquake. The contents described in the seismic PSA implementation standard accurately identified about the troubles and accidents occurred at the NCO earthquake. It clearly showed further usability of seismic PSA.

\section{OUTLINE OF TSUNAMI PRA AND ITS USABILITY [3], [5], [7]}

\subsection{Tsunami PRA Procedure}

The procedure of tsunami PRA consists of 4 steps as shown in Fig. 11.

- Step 1: Collection of plant information and setting of accident scenarios

- Step 2: Tsunami hazard evaluation

- Step 3: Fragility evaluation

- Step 4: Accident sequence evaluation

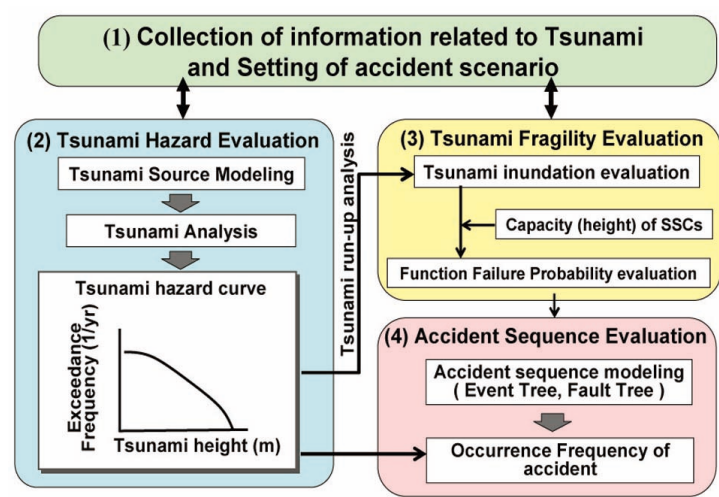

Fig. 11. Procedure of Tsunami PRA

\subsection{Collection of Plant Information and Setting of Accident Scenarios}

In the collection of information and setting of accident scenarios as shown in Fig. 12, the first step is to gather relevant information. Then, a "plant walk-down" based on the gathered information should be conducted. Finally, various accident scenarios based on the gathered relevant information and the result of the "plant walk-down" as shown in Fig. 12 should be set.

The accident scenarios should be identified by dividing the cases for tsunami run-up and backwash. The following accident scenarios are assumed in case of tsunami run-up as shown in this figure: 


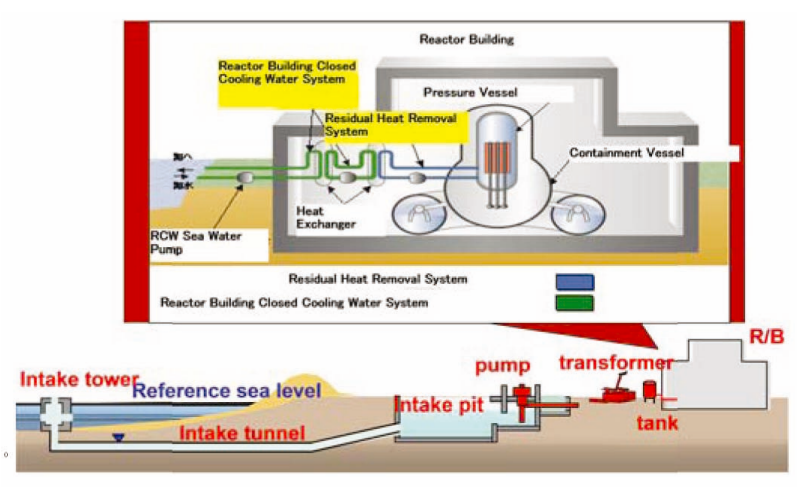

Fig. 12. Collection of Plant Information and Setting of Accident Scenarios

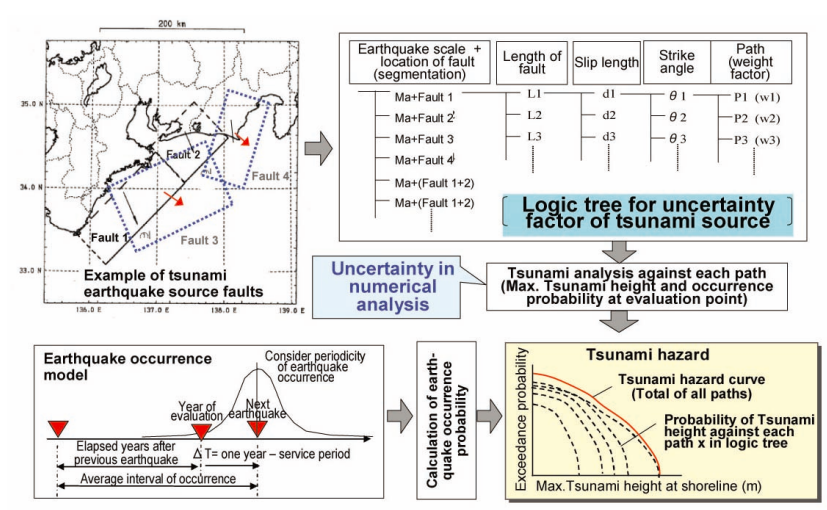

Fig. 13. Procedure of Tsunami Hazard Evaluation

- Function loss of sea water pump

- Functional loss of power supply system

- Functional loss of DG oil tank

- Function loss of sea water intake pit

- Function loss of sea water facilities by debris flow attack

- Functional loss of sea water intake function by deposition of sea sand

- Turn over of sea water pump cause by tsunami backwash

\subsection{Tsunami Hazard Evaluation}

The tsunami hazard evaluation is shown in Fig. 13. The tsunami hazard evaluation is defined by the tsunami wave height at shoreline and its exceedance frequency.

In cases of evaluating tsunami hazard, tsunami source models for both near-field active faults and far-field earthquakes such as the recent Chilean earthquake should be set. Then, ocean floor topographic models should be set by dividing it for far-field and near-field. In addition, onshore topographic models need to be set to evaluate onshore run-ups.

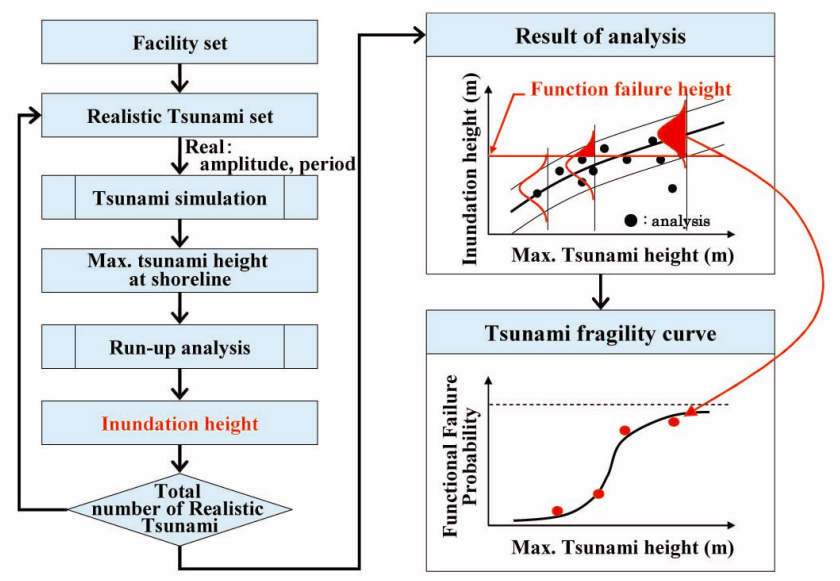

Fig. 14. Procedure of Tsunami Fragility Evaluation

The logic trees (LTs) are developed by considering uncertainties of tsunami source models, ocean floor topographic models and onshore topographic models. Conducting tsunami simulation for paths of each LT should then be done to obtain a tsunami hazard curve. The tsunami hazard curve is needed to obtain in cases of both tsunami run-ups and tsunami backwash.

\subsection{Tsunami Fragility Evaluation}

\subsubsection{Procedure of Tsunami Fragility Evaluation}

Fig. 14 shows the procedure for tsunami fragility evaluation. To make a fragility evaluation of a tsunami, fragility curves are obtained as the conditional probability that tsunami wave height exceeded the installation height of targeted structures and components as shown in Fig.14.

Tsunami wave heights are evaluated by conducting an analysis of onshore run-ups to the area that targeted buildings, structures and components are installed. This can help investigators and researchers evaluate uncertainties and dispersion of the wave heights of tsunami wave run-ups.

\subsubsection{Damage Part, Damage Mode and its Physical Quantities for Evaluation of Tsunami Fragiliti- es}

It is important to identify the parts and modes on function failure due to tsunami in cases of targeting facilities outside and inside of buildings. It is also important to identify their functional failure limits and the intensity of the tsunami. The tsunami intensity is measured by tsunami wave height, tsunami wave force, scour etc.

The failure parts, failure modes and physical quantities representing functional failure limits are different for each targeted structure and component. For quantitative evaluation of tsunami margins, attention should be paid to the fact that physical quantities representing margins would differ. 
The failure parts and failure modes to be evaluated are also different based on targeted structures and components.

\subsubsection{Examples of Fragility Evaluation}

Fig. 15 shows an example of fragility evaluation. The results on the analysis of onshore run-ups of tsunami are shown for targeted points in the Fig. 15. Fig. 15 shows the result of fragility evaluation in the case of assuming the installation point of the reactor building is $600 \mathrm{~m}$ from the shoreline, and function failure occurs when tsunami run-ups reach the building.

\subsection{Accident Sequence Evaluation}

In the case of evaluating accident sequences, the accident sequences are represented by using event trees based on various accident scenarios considered in 3.2. The evaluation procedure as shown in Fig. 16 is the same as that of Seismic PSA (Hirano, 2008). The accident

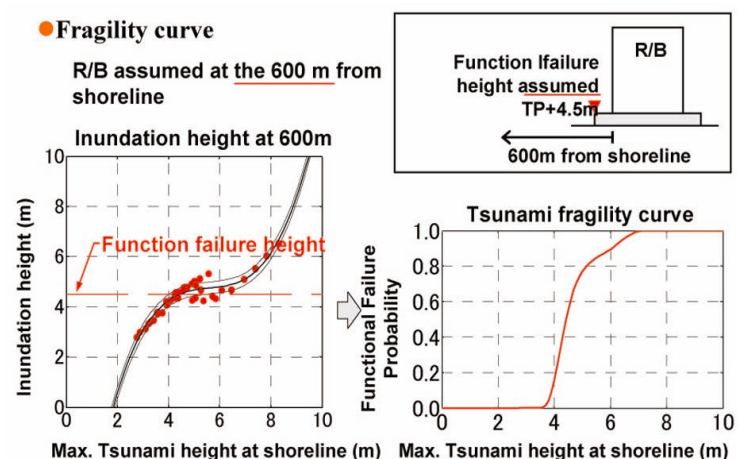

Fig. 15. Example of Tsunami Fragility Evaluation scenarios of tsunami are developed in cases of both tsunami run-ups and tsunami backwash.

\subsection{Usability of Tsunami PSA \\ 4.6.1 Identification Results of Accident Scenario by Tsunami PRA}

The accident scenarios of tsunami were identified in cases of both tsunami run-ups and tsunami backwash in the above section 3.2. In the tsunami run-up, the inundation of primary outdoor facilities was considered. For example, the loss of cooling function due to the inundation of the seawater pump, the loss of the off-site power due to the inundation of the power supply system, and the loss of the function of the emergency diesel generator due to the inundation of the oil tank. On the other hand, in the backwash, if the seawater pump level decreased below the minimum pump-able level in the storage pit, the cooling systems loss its function (Sugino, 2008).

Fig. 17 shows the event tree based on an accident scenario for tsunami run-ups in a BWR. The accident scenario starts from the function failure of facilities outside buildings and spreads out to functional failure inside buildings, before finally reaching core damage. When the outdoor facility is submerged in water, causing seawater pumping function loss, RCIC and HPCI are able to provide cooling function to the reactor core temporarily so that the reactor core will not suddenly break down. However, if the pumping system is not operational over a long period, the reactor core will be damaged.

Fig. 18 shows the event tree of an accident scenario for the backwash in the case of water drawing back causing water level decrease (Sugino, 2008).

If the mitigation system in both the run-up and the

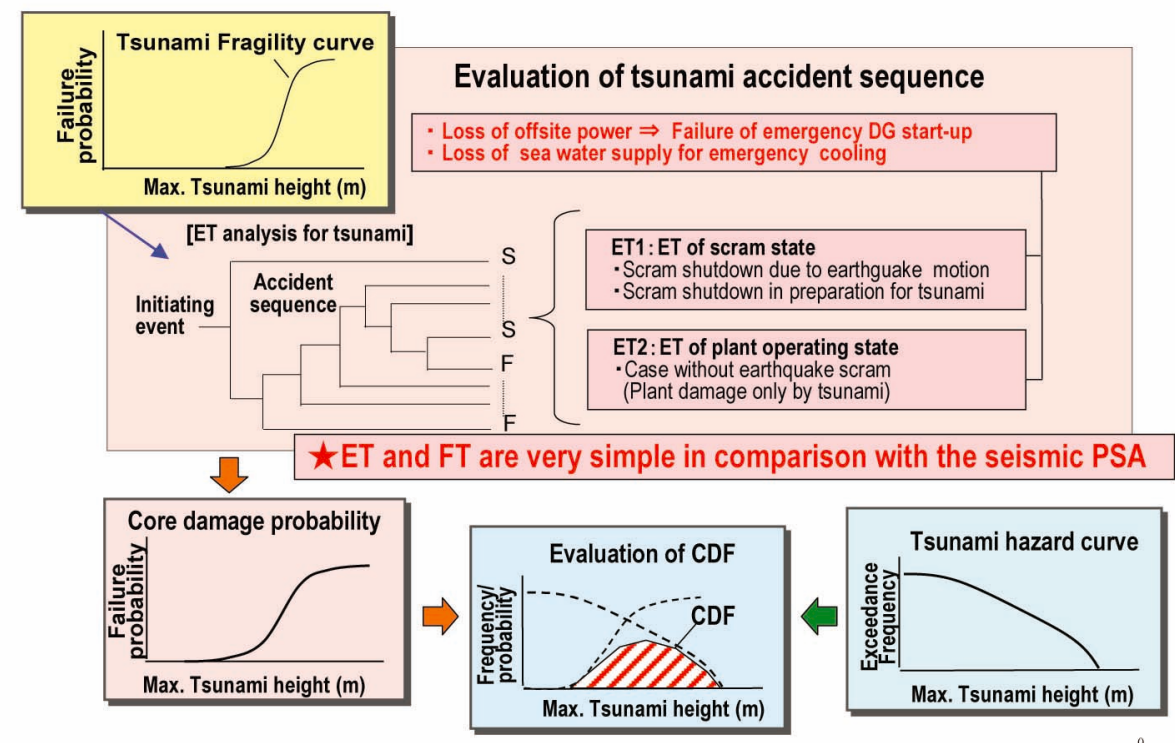

Fig. 16. Procedure of Tsunami Accident Sequence Evaluation 
backwash cannot be recovered within a short time, the reactor core will sustain damage. Approximate time from system malfunction until core damage is calculated in this case. In this case, the time is about 100 minutes (Sugino, 2008).

\subsubsection{Contents of the Accident at F1-NPP}

The contents of the accident at F1-NPP shown in Fig. 19 are as follows: [4], [9]

(i) Functional failure of seawater supply system (seawater pump, switchboard (switchgear) / signalprocessing board (motor control)) for seawater pump

(ii) Functional failure of emergency power supply system (diesel generator (DG), DG switchboard (switchgear) / signal-processing board (motor control)) for emergency power

(iii) Functional failure of breakers and emergency transformer in the switchyard

(iv) Functional failures of transmission line tower out of the site and off-site power supply

(v) Function failure of interconnected power supply between neighboring units (Units 1 and 2, Units 3 and 4, and Units 5 and 6).

(i) All of seawater supply systems and (ii) emergency power supply systems were lost in function simultaneously. These results from (i) to (v) led to loss of all AC power (Station blackout). As a consequence, functions of reactor

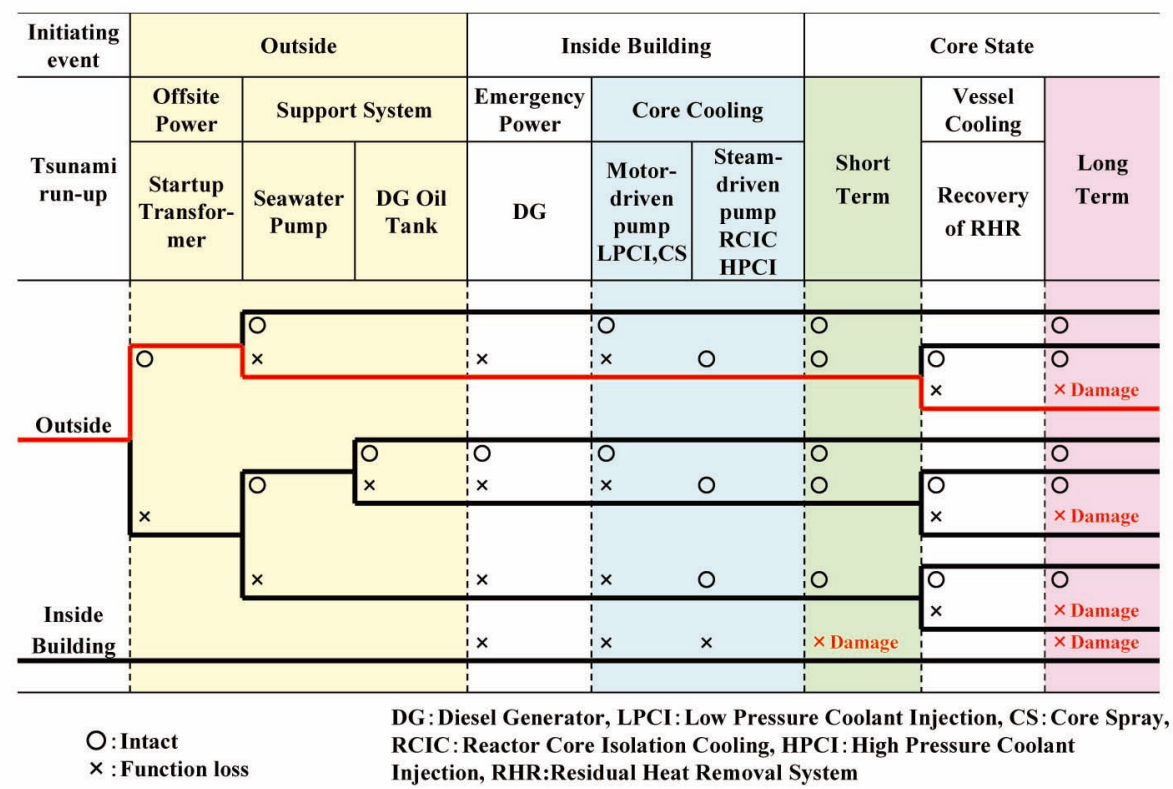

Fig. 17. Example of Event Tree Based on Accident Scenario of Tsunami Run-up

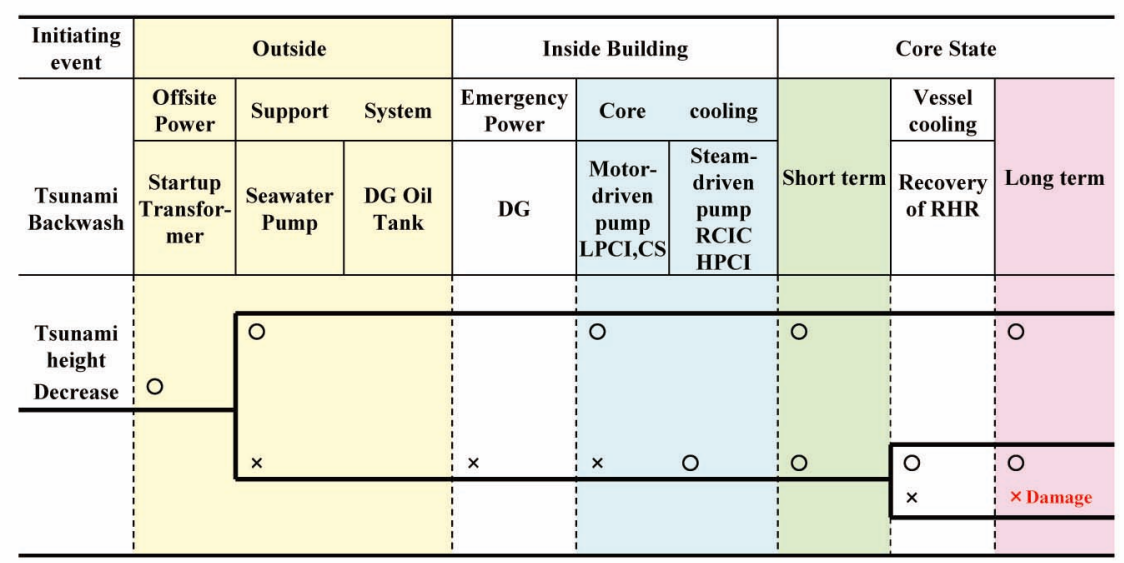

Fig. 18. Example of Event Tree Based on Accident Scenario of Tsunami Backwash 


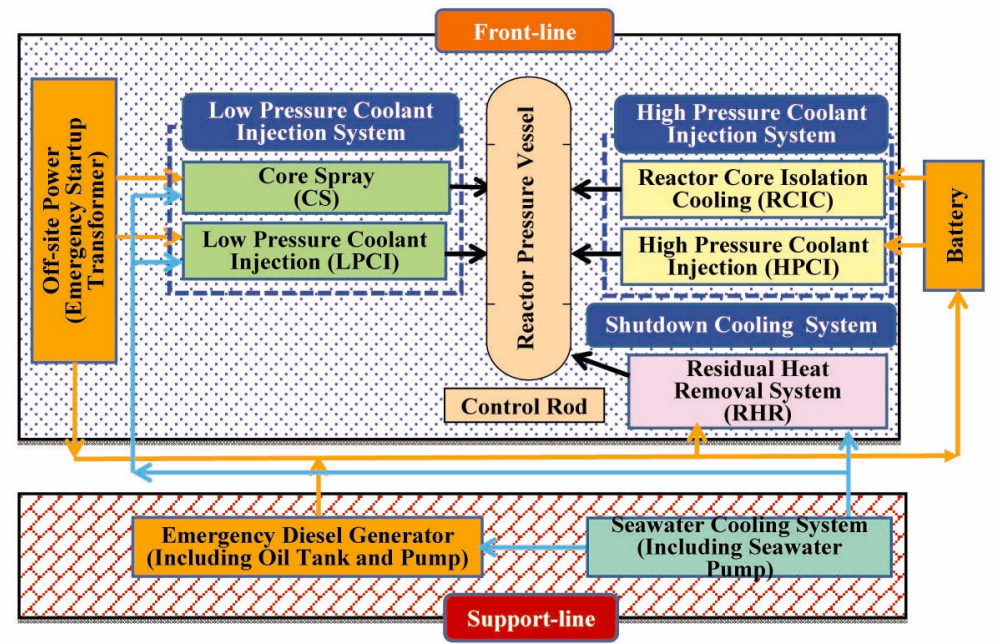

Fig. 19. Illustration of Contents of Accidents at F1-NPP

cooling system were lost, core damage occurred and radioactive materials were released to the off-site area.

\subsubsection{Comparison between Accident Scenarios by PSA and Accidents at F1-NP}

Table 2 shows the comparison results between the accident scenarios by tsunami PRA in 4.2 and the accidents at F1-NPP in 4.6.2 [4].

The contents of tsunami PRA developed more than a year ago accurately identified the accidents that occurred at the F1-NPP. It clearly showed further usability of tsunami PRA method.

\section{CURRENT ISSUES ON PRA REGARDING SEISMIC AND TSUNAMI EVENTS}

\subsection{Concepts of Methods for Evaluating Seismic Hazard Considering Gigantic Aftershocks}

\subsubsection{Status on Occurrence of Aftershocks [1]}

The total number of aftershocks recorded at 14:46 on March 11, 2011 after the Tohoku EQ is 444 for M greater than 5,76 for M greater than 6 and 6 for $M$ greater than 7 as shown in Fig. 20. M of the largest aftershock was 7.7 at 15:15 on March 11.The aftershock on April 7 then occurred and strong seismic motion was observed at Onagawa NPP. Finally, the aftershock on July 10 with M 7.3 occurred and a small tsunami was observed with the wave height of $12 \mathrm{cmat}$ Sendai port.

\subsubsection{Traditional Treatment of Gigantic Aftershocks on Seismic Hazard Evaluation}

Aftershocks lesser than M8 are excluded on "seismic PSA implementation standard of Japan Atomic Energy
Table 2. Comparison between Accident Scenarios by Tsunami PRA and Accidents at F1-NPP

\begin{tabular}{|l|l|}
\hline Accident Scenarios & $\begin{array}{l}\text { Accidents at } \\
\text { F NPPs }\end{array}$ \\
\hline (1) Failure of Sea Water Pump & Occurred \\
\hline (2) Failure of Power supply & Occurred \\
\hline (3) Failure of emergency DG & Occurred \\
\hline $\begin{array}{l}\text { (4) Failure of Transformer at } \\
\text { outdoor }\end{array}$ & Occurred \\
\hline (5) Inundation of reactor building & Unconfirmed \\
\hline (6) Inundation of turbine building & Occurred \\
\hline
\end{tabular}

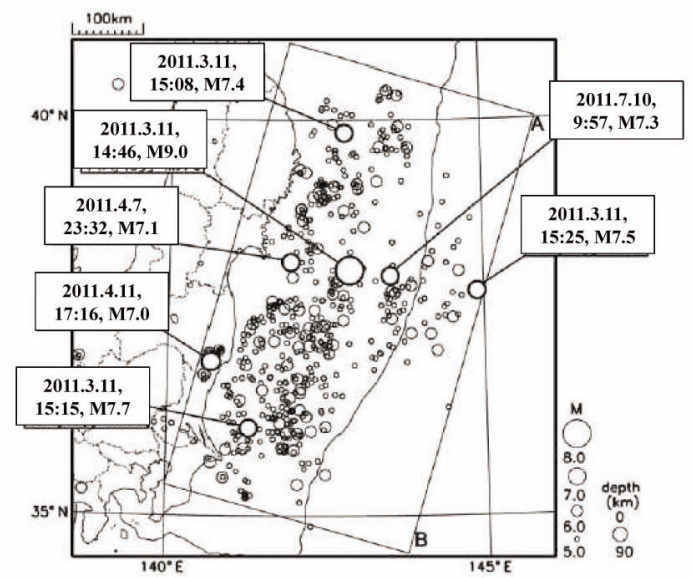

Fig. 20. Situation of Occurrence of Aftershock after 3.11 Tohoku Earthquake

Society [4]" because seismic motions of those level earthquakes would be not so strong and impacts on seismic hazard would be small. However $\mathrm{M}$ of the largest 


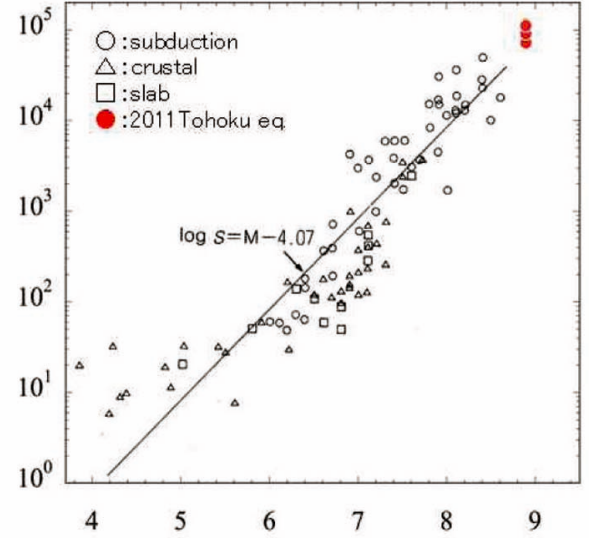

Fig. 21. Relationship between Fault Length and Magnitude Including 3.11 Tohoku Earthquake

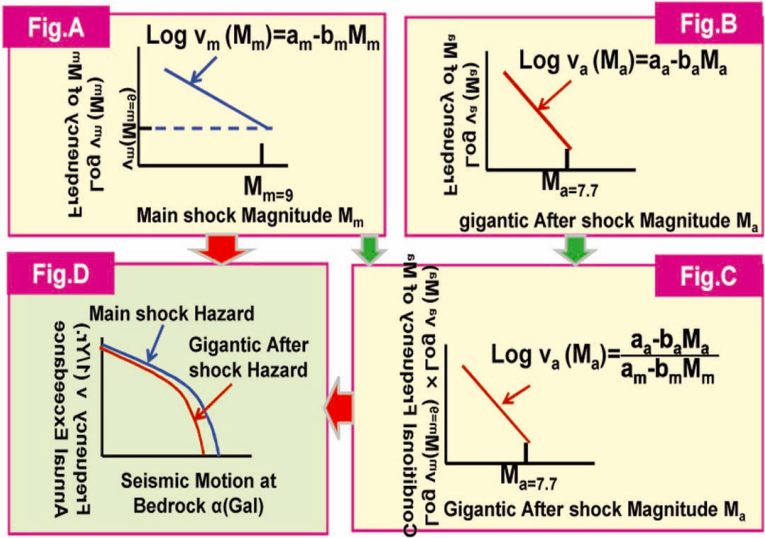

Fig. 22. Procedure of Seismic Hazard Evaluation for Gigantic Aftershock

aftershock of the Tohoku EQ was 7.7 and seismic motions of some aftershocks were observed that exceeded the amplitude of the design basis seismic ground motion. Therefore the impact of seismic motions for gigantic aftershock (GA) of M 9 class EQ should be considered.

In cases of evaluating seismic hazard for GA where the impact is not larger than those of the main shock, a judgment might be made whether to consider the risk evaluation or not.

\subsubsection{Concept for Evaluating Seismic Hazard Considering Gigantic Aftershocks}

The magnitude 9.0 of 3.11 Tohoku EQ obeys the relationship between fault length and magnitude as shown in Fig. 21. The authors propose a concept of Seismic Hazard Evaluation for GAs as shown in Fig.22.

(1) For evaluation of Seismic Hazard for GAs of M9 class EQs, confirmation should be made whether the

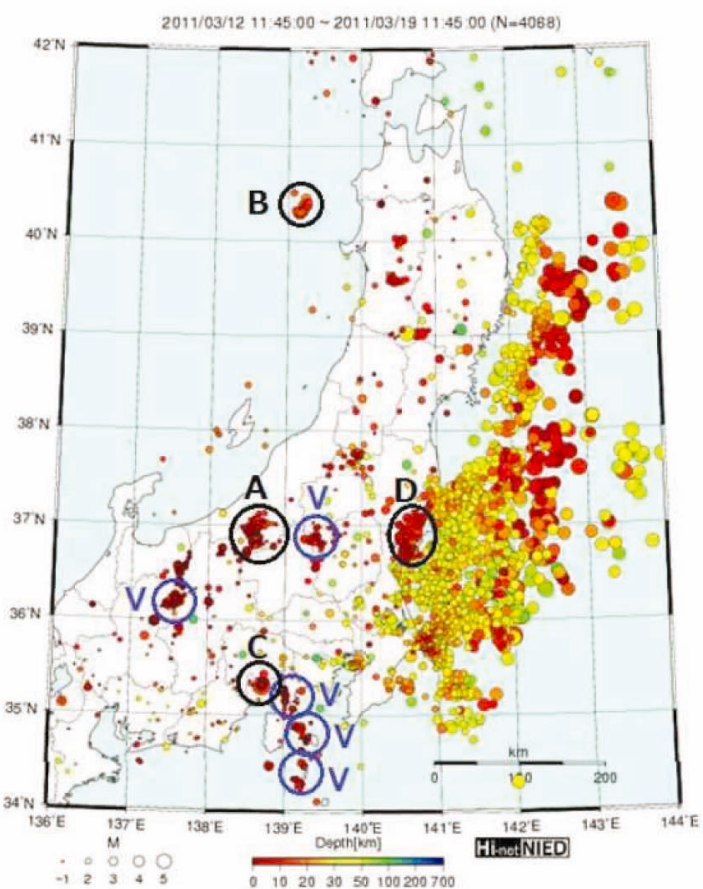

Fig. 23. Situation of Occurrence of Triggered Earthquakes after 3.11 Tohoku Earthquake

main shock (M9) follows the characteristics of the existing Gutenberg-Richter (G-R) equation.

(2) If it follows characteristics of the equation, obtain new G-R equation including the main shock (M9) as shown in Fig. A.

(3) Obtain occurrence frequency $v$ (M9) of M9 using new G-R equation of (2).

(4) Obtain regression equation for aftershocks of M9 as shown in Fig. B.

(5) Obtain regression equation as conditional probability with $v$ (M9) of (3) and regression equation of (4) as shown in Fig. C.

(6) Obtain seismic hazard of aftershock using the regression equation of (5) as shown in Fig. D

\subsection{Influence on Seismic Hazard of Triggered Earthquake}

\subsubsection{Status on Occurrence of Triggered Earth- quake [1]}

The occurrence of the triggered earthquake (TE) is shown in Fig. 23. TEs occurred all over Japan including Nagano, Akita, Shizuoka and Fukushima Prefectures. As for TEs near NPPs, a M6.7 TE occurred near the Tokamachi fault belt in the northern area of Nagano Prefecture approximately $50 \mathrm{~km}$ southeast from Kashiwazaki-Kariwa NPP on March 12. A M7.1 TE occurred near the Idozawa fault belt approximately $50 \mathrm{~km}$ southwest of F1-NPPin 
the Tohoku region on April 11. This TE was a normal fault-type earthquake with a tension axis that ran along a west-southwest to east-northeast direction, and which occurred at the shallow depth within the plate. The Tohoku Region is a region with a distinctive distribution of active faults in reverse faults, and this is the first time a normalfault-type inland earthquake was found.

\subsubsection{Examination of Values of " $a$ " and " $b$ " on Gutenberug-Rihiter Equation}

The activated triggered earthquakes such as magnitude 6 to 7 approximately are included in frequent occurrence after the 3.11 Tohoku EQ. Influence of them upon seismic hazards has not been considered so far. Therefore, the expected considerations are described below.

It is probable that the case in consideration of TEs or not which occurred after the Tohoku EQ have different values of "a" and "b" on Gutenberug-Rihiter Equation at the targeted area of seismic hazards evaluation. In order to confirm trends of probability, firstly, earthquake occurrence records should be accumulated and analyzed focusing on the five years leading up to the Tohoku EQ. Secondly, the values of "a" and "b" can be calculated by using data of the earthquake records for more than five years, before and after the Tohoku EQ.

The influence upon seismic hazards can be evaluated in the case of different values of " $a$ " and " $b$ " taking account of before and after Tohoku EQ, particularly when considering the effects of approximate magnitude 6 to 7 TEs.

\subsection{Concept of Correlation of Hazard and SSCs for SPRA at Multi Units and Sites}

\subsubsection{Lessons Learned from NCO EQ}

The Niigata-ken Chuetsu-oki Earthquake (NCOE) occurred near Kashiwazaki-Kariwa NPP (KK NPP) on July 17,2007 . KK NPP consists of 7units. In the NCO $\mathrm{EQ}$, the seismic motion accelerations observed at the building foundations of Unit KK1 to Unit KK7 exceeded the seismic response of design basic EQ S2 as shown in Fig.24. In addition, the PGA at KK1 is about 2 times stronger than KK5 because of the particular amplifying effect of the irregular underground structure. From the knowledge of NCOE, it is necessary to consider the correlations of input seismic motions at the site which has an irregular underground structure.

\subsubsection{Characteristics of Multi Units and Sites}

Seismic ground motion influence on the region is about $150 \mathrm{~km}$ in radius on the seismic hazard of Japan. There are multi units and sites in the region such as Wakasa region with 14 units and 5 sites in Japan as shown in Fig. 25. The standardization of the plant seismic design in Japan has been advanced. However, under strong seismic motion, it is very likely that various structures and components at multi units and sites would fail at the same time.

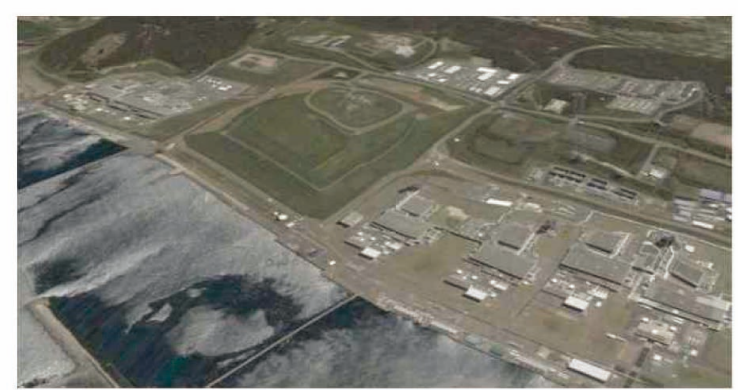

Fig. 24. Location of Kashiwazaki-Kariwa NPP with 7 Units at Japan

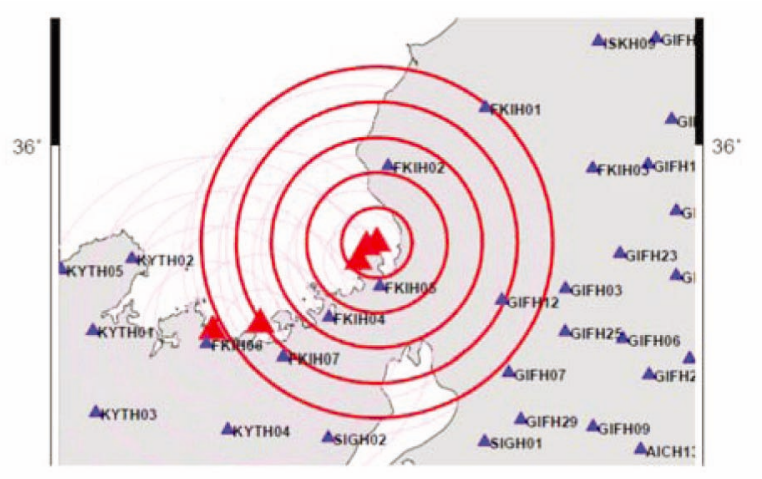

Fig. 25. Location of Wakasa Region with 14 Units and 5 Sites at Japan

\subsubsection{Concepts of Failure Correlation Under Seismic Motion at Multi Units and Sites}

JNES has been studying from the viewpoint of "Correlated Seismic Motion Methodology", "Correlation of component' response in the buildings at the same site" and "multi-unit and site evaluation methodology" as shown in Fig. 26.

In particular, in the project of "correlated seismic motion methodology", JNES will perform the correlation analysis of the observed EQ ground motion which was/ was not affected by the irregular underground structure and develop the prediction method of seismic motion which considers the above correlation.

In addition, it is necessary to determine the "Safety Goal" and "Performance Goal".

\subsubsection{Concepts Regarding Influence on CDF of Failure Correlation}

Concepts regarding influence on Core Damage Frequency (CDF) of failure correlation are shown in Fig. 27. $\mathrm{CDF}_{\mathrm{j}}$ and $\mathrm{CDF}_{\mathrm{k}}$ are $\mathrm{CDF}$ of unit $\mathrm{j}$ and unit $\mathrm{k}$ respectively. $\mathrm{CDF}_{\mathrm{j}}$ is bigger than $\mathrm{CDF}_{\mathrm{k}}$. The lift case in Fig. 27 is complete independence and failure correlation coefficient $r$ between unit $\mathrm{j}$ and unit $\mathrm{k}$ is 0 . Since there is no overlap 


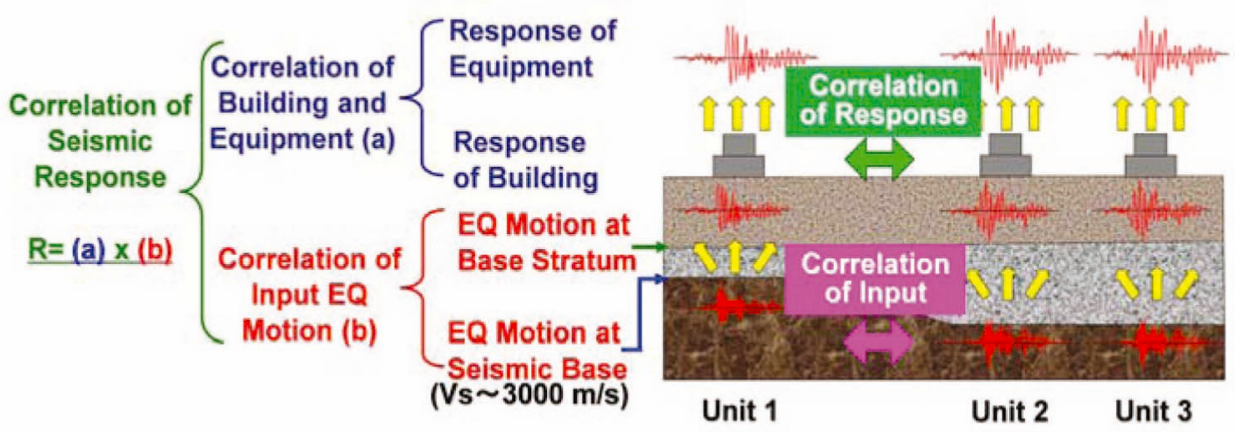

Fig. 26. Concept of Evaluation of Response Correlation
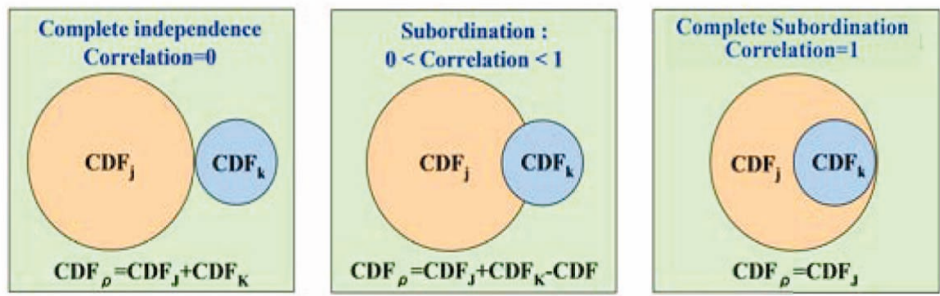

$\mathrm{CDF}_{j}$ : $\mathrm{CDF}$ of unit $\mathrm{j}, \mathrm{CDF}_{\mathrm{k}}$ : $\mathrm{CDF}$ of unit $\mathrm{k}, \mathrm{CDF}_{\mathrm{jk}}$ : Overlap area of $\mathrm{CDF}_{j}$ and $\mathrm{CDF}_{\mathrm{k}}$

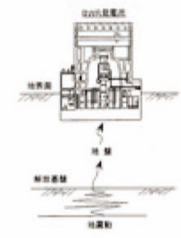

Unit J

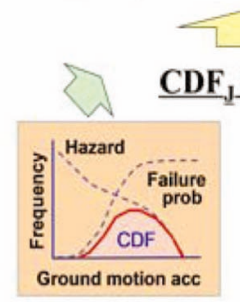

$\mathrm{CDF}_{\mathrm{J}}$

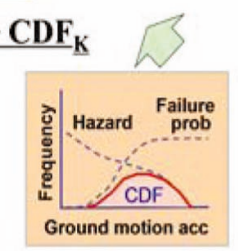

$\mathrm{CDF}_{\mathrm{K}}$

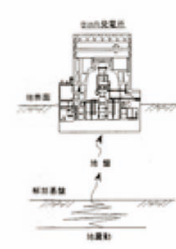

Unit K

Fig. 27. Concept Regarding Influence on CDF of Failure Correlation

area of $\mathrm{CDF}_{\mathrm{j}}$ and $\mathrm{CDF}_{\mathrm{k}}$, total $\mathrm{CDFr}$ is $\mathrm{CDF}_{\mathrm{j}}+\mathrm{CDF}_{\mathrm{k}}$. The right case is complete subordination and $\mathrm{r}$ is $1 . \mathrm{CDF}_{\mathrm{k}}$ is involved in $\mathrm{CDF}_{\mathrm{j}}$. Total CDFr is $\mathrm{CDF}_{\mathrm{j}}$. The center case which is the most real case is subordination and $r$ is the range between 0 and $1 . \mathrm{CDF}_{\mathrm{j}}$ is overlapped with the part of $\mathrm{CDF}_{\mathrm{k}}$. Total CDFr is calculated $\mathrm{CDF}_{\mathrm{j}}+\mathrm{CDF}_{\mathrm{k}}-$ overlap area of these CDF.

The $r$ obtains the following equation. In the equation (3), the first item is correlation of plant response. The second item is correlation of plant capacity.

$$
\begin{aligned}
& \rho_{j, k}=\frac{\beta_{R j} \cdot \beta_{R k}}{\sqrt{\beta^{2}{ }_{R j}+\beta^{2}{ }_{S j}} \cdot \sqrt{\beta^{2}{ }_{R k}+\beta^{2}{ }_{S k}}} \cdot \rho_{R j, R k}
\end{aligned}
$$

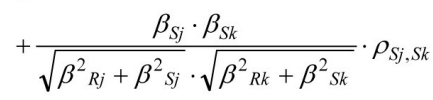

Where $r_{R j, R k}$ is the correlation coefficient of response between component $\mathrm{j}$ and $\mathrm{k} . b_{R j}$ and $b_{R k}$ are the logarithmic standard deviation of response of unit $\mathrm{j}$ and unit $\mathrm{k}$ respec- tively. $r_{S j, S k}$ is the correlation coefficient of capacity between unit $\mathrm{j}$ and unit $\mathrm{k} . b_{S j}$ and $b_{S k}$ are the logarithmic standard deviation of capacity of $\mathrm{j}$ and $\mathrm{k}$.

The authors have conducted the quantitative evaluation of r. Estimation Conditions are as follows. Buildings are the BWR reactor building and heart exchange building.

\subsection{Concepts of Seismic-tsunami PRA Methodology at Multi Units and Sites [5]}

\subsubsection{Concepts of Development}

The concepts and important issues for developing seismic-tsunami PSA methodology considering the combination of seismic and tsunami events at multi-units are described.

\subsubsection{Setting of Accident Scenarios}

Four cases of seismic and tsunami accident scenario are shown in Fig. 28; 


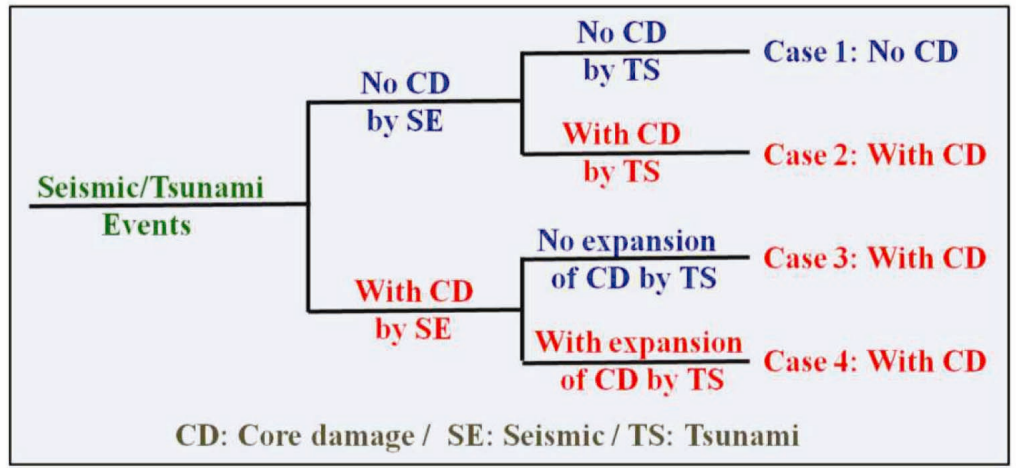

Fig. 28. Cases of Accident Scenarios on Seismic-tsunami PSA

Case 1: Seismic (no CD) and Tsunami (no CD),

Case 2: Seismic (no CD) and Tsunami (with CD),

Case 3: Seismic (with CD) and Tsunami (no CD) and

Case 4: Seismic (with CD) and Tsunami (with CD).

These scenarios include the loss of safety functions in structure, system and component having some safety functions, or deteriorating performance.

\subsubsection{Seismic-tsunami Hazard Evaluation}

The hazard for the external event at the multi-unit NPPs is evaluated. Seismic and tsunami hazard evaluations are practiced by developing hazard curves for seismic motion and tsunami height, respectively as shown in Fig. 29. They are plotted against annual frequency of exceedance. Seismic hazard curves and tsunami hazard curves are not independent because they are based on common seismic events. But different nature of strong seismic motion (period range: $0.1 \sim 1 \mathrm{sec}$ ) and tsunami rise time (period range: $10 \sim 120 \mathrm{sec}$ ) requires careful consideration of their source characterization. Because of such difference in period ranges, correlated seismic motions at multi-unit locations should be considered, while tsunami height can be treated as more or less uniform within a single site.

\subsubsection{Seismic-tsunami Fragility Evaluation}

In fragility evaluation, structures and components of multi-unit reactors are covered and correlation of their failures should be considered. The functional failure probability (fragility: $\mathrm{F}_{\mathrm{i}}^{\mathrm{S}-\mathrm{T}}(\alpha, \mathrm{h})$ ) with conditions that an arbitrary component "i" will secure its function against seismic motion $\alpha$ but fail against tsunami $h$ is represented as equation (1) and shown in Fig. 30

$$
\mathrm{F}_{\mathrm{i}}^{\mathrm{S}-\mathrm{T}}(\alpha, \mathrm{h})=\overline{\mathrm{F}_{\mathrm{i}}^{\mathrm{S}}(\alpha)} \times \mathrm{F}_{\mathrm{i}}^{\mathrm{T}}(\mathrm{h})=\left(1-\mathrm{F}_{\mathrm{i}}^{\mathrm{S}}(\alpha)\right) \times \mathrm{F}_{\mathrm{i}}^{\mathrm{T}}(\mathrm{h})
$$

Where $F_{i}^{S}(\alpha)$ and $F_{i}^{T}(h)$ are functional failure probability of component "i" against $\alpha$ and $h$, respectively. $\overline{F_{i}^{S}(\alpha)}$ is functional success probability of component "i" against $\alpha$.

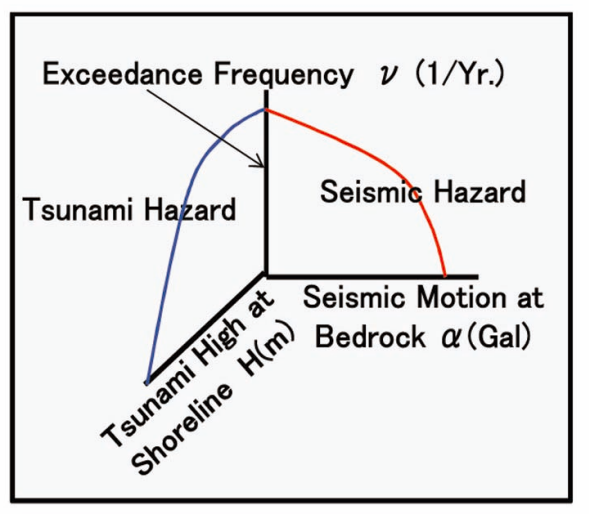

Fig. 29. Definition of Hazard on Seismic-tsunami PSA

In seismic-tsunami fragility evaluation, it is important to consider the fatigue effect of structure and component under seismic motions by main shock and gigantic aftershocks.

\subsubsection{Seismic-tsunami Accident Sequence Evalu- ation}

In accident sequence evaluation, accident sequence evaluation targets all 4 accident scenarios as shown in Fig. 28. The CDF which considers the case of earthquake (EQ) coupling with tsunami (TS) is resulted by the addition of the TS events' CDF (Case 2) to the EQ events' CDF (Case 3 and 4). The case 2 includes scenarios of core damage (CD) caused by TS following an earthquake which brought loss of safety functions in structure, system and component (SSC) having some safety functions, or deteriorating performance. In Case 3, some SSCs could have functional failure by TS. In Case 4, the CD which is induced by EQ is expanded by TS.

Although the case of CD which is induced by EQ/TS almost results in the loss of function in the containment vessel, it is important for Level 2 PSA to make detailed 


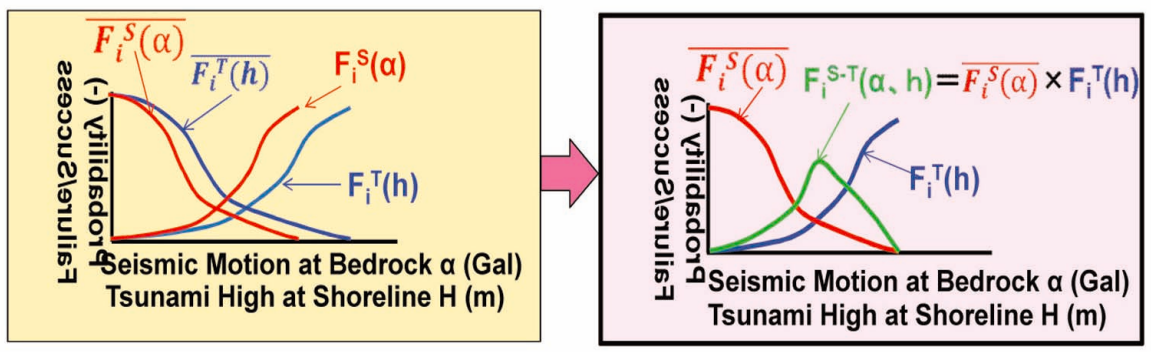

Fig. 30. Concept of Fragility Evaluation on Seismic-tsunami PSA

classification and determination of the accident sequence, because of big differences in terms of the source (kind of radioactive materials, chemical characteristics, emissive quantity and periods) for each scenario

\section{CONCLUSIONS}

The summarizations of this paper are as follows:

(1) Current issues of seismic engineering

The current issues of seismic engineering based on lessons learned from F1-NPP accident are as follows:

i) Occurrence of gigantic main earthquake and tsunami, and combination of seismic hazard and tsunami hazard

ii) Consideration of gigantic aftershock and triggered earthquake

iii) External events risk evaluation at multi-units and sites

iv) Combined emergency of both natural disaster and nuclear accident

v) Core damage during short time based on functional failure of support systems(seawater supply, power supply and signal systems)

vi) Common cause failure of multi structures and components

vii) Dependency among neighboring units

(2) Usability and application of PSA

i) PSA is a usable method to identify important accident sequences, systems and components for safety and these results are candidates to take countermeasures as accident managements (AMs).

ii) PSA is an effective measure to evaluate AM's effectiveness.

(3) Current issues on PRA regarding seismic and tsunami events

The authors expressed the below current issues on PRA regarding seismic and tsunami events and also made reference to the concept and procedure to resolve their issues:

i) Concepts of methods for evaluating seismic hazard considering gigantic aftershocks ii) Influence on seismic hazard of triggered earthquakes

iii) Concepts of correlation of hazard and SSCs for SPRA at multi units and sites

iv) Concepts of seismic-tsunami PRA methodology at multi units and sites

\section{ACKNOWLEGEMENTS}

The authors would like to express their appreciation to the valuable suggestions and recommendations in various fields related to this work from Prof. Emidiety K. Kameda and Prof. M. Hirano.

\section{REFERENCES}

[1 ] Japanese government: "Report of Japanese government to the IAEA ministerial conference on nuclear safety", 2011.

[2 ] HIRANO, M., Nakamura, T. and Ebisawa, K.: "Outline of seismic PSA implementation standards on the atomic energy society of Japan", The $14^{\text {th }}$ World Conf. on Earthquake Engineering, Oct. 12-17, Beijing, China, 2008.

[3 ] SUGINO, H., Iwabuchi, Y., Nishino, M., Tsutsumi, H., Sakagami, M. and Ebisawa, K.: "Development of probabilistic methodology for evaluating tsunami risk on nuclear power plants", The $14^{\text {th }}$ World Conf. on Earthquake Engineering, Oct. 12-17, Beijing, China, 2008.

[4] Japan of Nuclear Atomic Society: Seismic Probabilistic Safety Assessment Implementation Standards, 2009.

[ 5 ] EBISAWA, K., KAMEDA, H., and HIRANO, M.: "Concept for developing seismic-tsunami PSA methodology considering combination of seismic and tsunami events at multi-units", Proceeding of the One Year after 2011 Great East Japan Earthquake - International Symposium on Engineering Lessons Learned from the Giant Earthquake-, Tokyo, 2012.

[6] EBISAWA, K.: Current status and important issues on seismic hazard evaluation methodology in Japan, Nuclear Engineering Technology, Vol. 41, NO.10, Korea, December 2009.

[7] Katsumi Ebisawa, Hideharu Sugino, Yoko Iwabuchi and Masaki Nishio: Usability of tsunami PRA based on Fukushima-daiichi NPP accident under 2011 Tohoku tsunami, The $15^{\text {th }}$ World Conf. on Earthquake Engineering, Sep. 24-28, Lisbon, Portugal, 2012.

[8] KAMEDA, H. : "Engineering agenda on earthquaketsunami safety of nuclear power plants raised by the 2011 
Great East Japan Earthquake disaster", Proceeding of the One Year after 2011 Great East Japan Earthquake International Symposium on Engineering Lessons Learned from the Giant Earthquake-, Tokyo, 2012.

[9] TAKAMATSU, T. KAMEDA, H., and Ebisawa, K. : "Fragility enhancement in seismic-tsunami risk reduction for nuclear power plants", Proceeding of the One Year after 2011 Great East Japan Earthquake - International Symposium on Engineering Lessons Learned from the Giant Earthquake-, Tokyo, 2012.
[10] IAEA: IAEA Works to Protect Nuclear Power Plants Against Tsunami and Flooding Hazards. http://www.iaea. org/newscenter/news/2010/bravingwaves.html

[11] Katsumi Ebisawa, Hiroyuki YAMADA, Hideto TAOKA, Kyoko SANO, Hideaki TSUTSUMI, Naoto TAKAMATSU, Shohei MOTOHASHI and Hiroyuki KAMEDA: Development of information system for post-earthquake Plant evaluation and evacuation support, The $14^{\text {th }}$ World Conf. on Earthquake Engineering, Oct. 12-17, Beijing, China, 2008. 